\title{
O dilema do controle e a falha sequiencial nas reformas gerenciais
}

\author{
Flávio da Cunha Rezende
}

\section{A falha seqüencial nas políticas de reforma administrativa}

As reformas administrativas são políticas públicas, cujo objetivo último é a elevação da performance de um dado sistema burocrático. Diante de um declínio de performance, ou mesmo da necessidade de introduzir ganhos de eficiência, efetividade e eficácia na administração pública, os governos formulam políticas e programas governamentais voltados para criar as condições necessárias para a elevação da performance. As reformas administrativas usualmente são programas que se voltam para elevar a performance por meio da ação combinada em dois fronts:

a) introduzir ganhos de racionalidade na gestão financeiro-fiscal do Estado; e

b) promover um conjunto de mudanças institucionais visando às transformações nas estruturas de controle, gestão e delegação entre as diversas partes do sistema burocrático.

Neste sentido, pode-se dizer que as reformas administrativas buscam atingir, em simultâneo, o ajuste ou equilíbrio fiscal e a mudança institucional. Os casos mais clássicos e abrangentes destas políticas são os programas nacionais de reforma que assumiram diversas formas, a depender do contexto histórico em que são formulados e implementados, bem como de seus objetivos específicos. No Brasil, por exemplo, a trajetória histórica de reforma da administração federal foi iniciada no Estado Novo, com Getúlio Vargas e o Dasp, atingindo a Reforma Gerencial de 1995.

Na história recente do Estado moderno, são freqüentes as tentativas de reformar o Estado e a administração pública, e, ao mesmo tempo, tem

Flávio da Cunha Rezende é professor/ pesquisador de mestrado em Ciência Política da Universidade Federal de Pernambuco; PhD em Políticas Públicas e Planejamento, pela Cornell University, Ithaca, EUA.

Contato: fcrzen@ elogica.com.br 
se tornado uma experiência freqüente a incapacidade destas políticas em promoverem ganhos substanciais de performance no setor público. $\mathrm{Na}$ trajetória acumulada de reformas administrativas (em nível nacional ou sub-nacional), é nítido o fenômeno recorrente de que as reformas tendem a falhar seqüencialmente, e os problemas de performance persistem. As reformas dificilmente conseguem atingir os seus objetivos, problemas de performance persistem, e novas reformas são formuladas e implementadas para lidar com "antigos problemas" e, neste sentido, pode-se dizer que elas falham seqüencialmente. $\mathrm{O}$ caso brasileiro historicamente representa um modelo de falha seqüencial, i.e., as reformas dificilmente conseguiram alterar a performance do aparato burocrático. Baixa performance e elevados gastos têm sido razões para novas reformas, porém, os “crônicos problemas" persistem: clientelismo, corrupção, reduzida eficiência, reduzido grau de profissionalismo, elevados gastos e déficits no setor público, bem como outros males burocráticos. A reforma gerencial brasileira de 1995 foi centrada na questão de como promover a melhoria da performance no setor público brasileiro, trazendo a necessidade de combinar ajuste fiscal e mudança institucional. O que interessa mais de perto neste artigo não é examinar casos concretos de reformas e avaliar em que medida elas se aproximam ou se afastam deste padrão empírico específico, mas apresentar um conjunto de razões para tal fenômeno, i.e., por que razões as reformas administrativas tendem a falhar seqüencialmente? ${ }^{1}$

A falha seqüencial das reformas administrativas e a decorrente persistência dos problemas de performance no aparato burocrático se evidenciam na simples observação empírica de que as reformas são rápidas e freqüentemente "descontinuadas, abandonadas, terminadas". As reformas são políticas que se caracterizam por serem "muito fáceis de iniciar, porém, muito difíceis de manter". Raros são os casos concretos em que as reformas persistem no tempo e conseguem manter os propósitos originais para os quais elas foram formuladas. O problema da falha sequiencial deriva do fato simples de que as reformas dificilmente atingem seus objetivos propostos, ou mesmo problemas de cooperação com os objetivos propostos inibem a elevação da performance. As reformas administrativas são políticas de baixa performance e existem razões diversas para tal fenômeno.

Ao iluminar a natureza de falha seqüencial, não quero dizer que as reformas sejam fatalmente casos completos de falha, ou mesmo, que estas são "fadadas" ao fracasso. As chances de falha seqüencial dependem em muito das escolhas dos atores estratégicos em cooperar com suas propostas de reformas, contudo, existem certos fatores contextuais e características que potencializam o problema da falha seqüencial, entre os quais a literatura destaca: 
a) o fator democracia - no qual se supõe existir uma correlação direta e negativa entre contextos democráticos e sucesso de implementação das reformas, uma vez que nas democracias as reformas não podem ser implementadas de "cima para baixo", por decreto, e, sim, dependem da construção de coalizões políticas com diversos setores burocráticos, tornando complexo o problema do consenso em torno dos objetivos programáticos;

b) o fator baixa performance - no qual se supõe que quanto mais problemática seja a performance no setor público, mais difícil é a implementação das reformas. Em contextos em que existe um grande legado de baixa performance, dificilmente setores da burocracia associam ganhos advindos da elevação da performance, inibindo a cooperação com políticas de reforma orientada pela performance;

c) a relação direta entre descentralização e desequilíbrio fiscal, em que se supõe que, quando a descentralização tem produzido historicamente problemas de equilíbrio fiscal, novas tentativas de expandir a descentralização são obstaculizadas por agendas de controle fiscal. A prioridade pelo ajuste fiscal, nestes casos, está diretamente associadas ao maior grau de controles burocráticos, inibindo propostas de ampliação de elementos necessários a performance, tais como: autonomia, responsabilidade e redução dos controles tradicionais. Nestes contextos, se evidencia uma associação direta da performance com mais controles, e não o contrário. Quando estes fatores atuam isoladamente ou de modo combinado, maiores são as chances de que as reformas administrativas não consigam obter a cooperação simultânea com os dois objetivos, reduzindo as chances de implementação. Na raiz das reações, a reforma, todavia, reside a questão importante da demanda por controle. Quando os interesses em torno da questão do ajuste fiscal e da mudança institucional demandam controle de forma compatível, e não contraditória, demonstram os casos no mundo real, é possível alinhar os interesses em torno de uma agenda comum para implementar a reforma. Quando não, as chances para a falha seqüencial são consideráveis.

As reformas gerenciais dos anos 90 são casos típicos de reformas que trazem em si uma demanda contraditória por controle, produzindo incentivos para a falha seqüencial. Caiden (1999) sugere, com base em uma ampla amostra de políticas de reformas, que a falha seqüencial persista:

"Em escala mundial, as administrações públicas estão sendo reexaminadas e remodeladas (...). O governo está sendo transformado e reinventado, a centralização burocrática está sendo abandonada, o welfare state está sendo reduzido em tamanho, o setor público esta sendo reduzido, as organizações do setor público estão passando por processos de reengenharia, e os princípios da gestão pública estão sendo revistos. Os governos têm prometido muito, mas, freqüientemente, eles falham em melhorar suas performances, pelo simples 
fato de que as reformas se mostram desapontadoras. As políticas de reforma não produzem impactos significativos; elas caminham na direção errada; ou são surpreendidas pelos fatos. Os reformistas têm sido bastante otimistas e muitas vezes irrealistas; elas usualmente têm caído nas armadilhas da implementação. As reformas precisam de apoio político, de setores populares, e ao mesmo tempo, gestão competente. As reformas levam tempo (...) é fundamental aceitar o que é 'possível atingir com as reformas num dado contexto', mesmo se estes resultados estiverem aquém de suas intenções originais". ${ }^{2}$

A falha seqüencial representa um gap temporal entre os resultados obtidos na implementação e os resultados pretendidos quando da formulação das reformas. O que a evidência empírica comparativa acumulada revela é que as reformas usualmente atingem resultados esperados. Os ganhos de performance usualmente são muito tímidos, e, muitas vezes, as políticas de reforma sofrem intensa resistência por parte dos setores-alvo das reformas.

Caiden (1991) conclui nesta direção e argumenta que existem várias dimensões nessas políticas que podem ser relacionadas com a falha seqüencial. Primeiro, existe a maior necessidade de tempo para apreender os resultados das reformas. As reformas administrativas são lentas quando comparadas com reformas políticas e econômicas. Em segundo lugar, o estágio da implementação é a fonte primordial da falha seqüencial. Em terceiro lugar, as novas reformas perseguem problemas antigos, indicando a natureza seqüencial da falha. As conclusões de March e Olsen (1983, 1989) sobre as reformas administrativas nos EUA ao longo deste século também se alinham com o argumento da falha seqüencial. Eles mostram que as iniciativas de reforma dificilmente produzem mudanças administrativas substanciais, e que estas não produzem impactos significativos sobre a redução e o controle dos custos administrativos, bem como sobre a eficiência, ou sobre as transformações na estrutura de controles burocráticos. As reformas têm sido um manancial de frustrações. Entretanto, como argumentam os autores, a necessidade contínua de reformar a administração pública se alastra governo a governo, indicando uma demanda permanente por reformas.

Sob diversos ângulos de visada, a vasta literatura sobre as experiências de políticas de reformas administrativas disponibiliza um amplo arsenal para este problema, e o próximo passo deste artigo é discorrer sobre estas explicações, buscando apreender o tipo de explicação, o mecanismo causal e os argumentos utilizados pelos diversos modelos analíticos para explicar a falha sequiencial nas reformas. 


\section{Desvendando as explicações para a falha seqüencial nas reformas administrativas}

A experiência cumulativa dos estudos de implementação das reformas administrativas no mundo desenvolvido e em desenvolvimento dispõe de um vasto conjunto de explicações para o seguinte problema: e "por que as reformas administrativas falham de modo sequiencial?". Nesta seção, trataremos das diversas explicações, diferenciando-as de acordo com o foco, o mecanismo causal e com a natureza do argumento.

A primeira linha explicativa centra suas atenções no fato de que as reformas administrativas usualmente são formuladas de maneira padronizada ("one size fits all”), desconsiderando a grande diversidade organizacional existente na burocracia moderna. Por esta razão, as reformas são incompatíveis com os "reais" problemas enfrentados pelas organizações da administração pública moderna, e tendem a representar formas "estilizadas" sobre o que deve ser feito para elevar a performance sem um maior conhecimento da realidade. Como muitos dos problemas de performance variam de acordo com as diversas agências administrativas do governo, as políticas de reforma muito dificilmente dão conta das especificidades e nuances necessárias para transformar efetivamente a performance, perdendo seu grau de operacionalização e de cooperação com os objetivos da reforma.

A segunda linha considerada aqui releva o fator institucionalização. ${ }^{3}$ Pelo fato de que as reformas administrativas procuram introduzir mudanças em ambientes altamente institucionalizados, grandes resistências organizadas se estruturam em torno das mudanças, e grandes são as oportunidades para a falha seqüencial. Esta explicação chama a atenção para o fato de que as reformas no setor público (que alguns chamam desinstitucionalização) são altamente complexas, lentas e dependentes de um esforço continuado de compromisso de um amplo conjunto de atores. As reformas administrativas envolvem elevados esforços para a transformação das regras do jogo, e dependem da formação de complexas coalizões políticas e da viabilidade de compromissos que dificilmente tendem a perdurar entre governos. A resistência à reforma e a falha seqüencial são resultados mais prováveis.

Kaufman (1995) relaciona a falha seqüencial à resistência organizada de setores burocráticos. Para ele, as razões da não cooperação com as reformas são estruturadas a partir dos seguintes fatores:

a) os benefícios advindos da manutenção do status quo;

b) a oposição calculada à mudança; e

c) a reduzida capacidade dos atores em realizar as mudanças necessárias em uma política de reforma.

As reformas enfrentam o conflito de interesses organizados entre aqueles que pretendem elevar a performance e aqueles que se beneficiam 
com a redução da mesma. Nesta perspectiva, a oposição organizada de setores burocráticos ocorre como resposta aos possíveis custos incidentes sobre tais setores com a elevação da performance. A elevação da performance não se constitui razão necessária e suficiente para a organização dos interesses em uma dada reforma. Pelo contrário, a sua elevação interessa a poucos atores. A manutenção do status quo e a minimização dos custos associados às reformas são os caminhos preferidos pelos diversos setores burocráticos. As reformas enfrentam intensa resistência, e propostas de melhoria da performance são usualmente obstaculizadas no plano político por setores burocráticos dotados de poder e influência na burocracia, e usualmente beneficiados com a manutenção do status quo. Kaufman (1995) explica melhor as razões da resistência na seguinte passagem:

"um conjunto de forças tende a manter a burocracia funcionando nos mesmos padrões. Os benefícios gerados pela manutenção e a oposição à mudança baseada no cálculo estratégico sobre custos e benefícios potenciais nas políticas de reformas representam as fundações sob as quais se assentam as resistências à reforma. Diversos fatores reduzem a capacidade das organizações do setor público para realizar reformas (...) considerável é o poder que tem estas forças para manter as organizações nos seus padrões habituais de comportamento, de forma que pode ser considerável surpreendente qualquer tentativa bem-sucedida de mudança. As reformas têm poucas chances de ocorrência. Este é um motivo pelo qual muitas organizações morrem antes mesmo de empreender mudanças mais significativas". 4

Light (1997), analisando ciclos de reformas administrativas nos EUA ao longo do século, explica de forma diferente tal problema. Para ele, a razão central da falha seqüencial reside nos efeitos não-intencionais produzidos pelas reformas. Ele argumenta que uma dada política de reforma produz mais demanda por reformas, como conseqüências não-intencionais da ação. Ele mostra que as reformas são políticas "incompletas", oscilando, em termos dos seus princípios, linhas de ação e propósitos entre velhas e novas filosofias de como reformar a administração pública. Ele considera que estas "filosofias" são quase sempre contraditórias, produzindo um ciclo permanente e conflituoso de reformas.

“É possível que uma política ou iniciativa de reforma anterior contribua negativamente para a atual reforma, dado um problema de contradição entre princípios, o que sugere haver uma necessidade contínua de reformas administrativas. Existe alguma evidência de que os ciclos de reforma ocorrem de forma muito acelerada, i.e, o intervalo entre a última reforma e a próxima está cada vez se tornando maior. Quanto mais o governo é reformado, mais o 
Congresso e a Presidência consideram necessário reformar.

Os ciclos de reforma conduzem a uma simples predição: os esforços atuais de reformar ou reconstruir a burocracia serão seguidos por uma retórica de reduzir o tamanho desta burocracia, e, depois por uma tentativa de livrar os gestores públicos (managers) desta mesma burocracia, e, assim sucessivamente. Dado que o Congresso e a Presidência não sabem exatamente o que fazer (e o que não fazer) para elevar a performance do setor público, e, pelo fato de não existir uma única teoria sobre como elevar a performance, as reformas oscilam entre novos e velhos princípios, quase sempre de forma errática. Muitas das reformas dos anos 90 parecem antagônicas às reformas dos anos 30, e estas são, em parte, uma resposta às reformas da Era Progressiva de 1900, que foram, em parte, respostas aos problemas de performance das iniciativas de state-building nos anos de 1860 e 1870, as quais eram uma resposta aos problemas de performance do Estado burocrático na época de George Washington, John Adams e Thomas Jefferson”. (Light, 1997, Tradução do Autor).

Coe (1997) propõe uma explicação a partir do conflito estrutural, uma conseqüência não-intencional das reformas. O conflito estrutural produz um deslocamento dos objetivos nas organizações que buscam implementar reformas administrativas. Ele argumenta que este conflito é gerado por pressões externas à organização, transformando os objetivos inicialmente perseguidos pelas reformas, e, em certos casos, tais forças produzem objetivos completamente antagônicos aos originalmente formulados. Este conflito resulta do fato de que, durante uma reforma, são perseguidos outros objetivos que não os formalmente expressos na agenda de reformas, abrindo reais possibilidades para a mudança ou deslocamento destes objetivos. Ele explica, por exemplo, que em uma reforma de dois objetivos, quando a ação é voltada para um dos objetivos, a atenção da organização se volta para o outro, e a ação se volta para o segundo objetivo, e vice-versa.

Existe, ainda, um conjunto de explicações que envolvem questões relativas à questão da incerteza, da complexidade e da ambigüidade presentes nas reformas. As reformas dificilmente conseguem atrair a atenção dos atores sociais, obtendo a centralidade na agenda por um tempo prolongado. Neste sentido, as reformas usualmente têm um considerável ímpeto inicial, o qual tende a se dissipar no tempo, reduzindo as chances de cooperação dos atores estratégicos com a agenda de reformas. Por outro lado, as reformas são consideradas políticas públicas que possuem múltiplos objetivos, elevada incerteza, e são dotadas de alto grau de contradição interna. March e Olsen (1983) argumentam que a falha seqüencial deriva do fato de que a incerteza e a multiplicidade de objetivos contraditórios desencadeiam problemas de cooperação com as reformas: 
"O cálculo político nas reformas é sensível às variações conjunturais e às mudanças de curto-prazo na atenção dos atores políticos. As decisões sobre a reforma parecem depender menos da natureza e propriedade das políticas (...) mas, sim, sobre os interesses de curto prazo dos atores políticos, sobre os quais os atores que conduzem as reformas têm pequeno grau de controle (...) Por outro lado, as reformas têm dificuldade de manter a atenção dos principais atores políticos (...) Presidentes, líderes no Congresso, grupos de interesse e funcionários de alto escalão na burocracia são usualmente muito ocupados para participar mais ativamente das reformas. Neste sentido, pode-se argumentar, que as reformas usualmente se processam dentro de um contexto de 'vácuo de atenção' (...) As reformas usualmente desviam e reduzem seu ímpeto inicial, tornando diretamente associadas com questões e projetos distantes da intenção inicial" (March e Olsen, 1983, Tradução do Autor).

Desveaux (1994) sugere que o problema da falha sequiencial nas reformas é produzido pelo alto teor de incerteza e ambigüidade nestas políticas. Ele considera que as reformas são políticas que se destinam a promover o controle de forma muito incerta; todavia, elas desconsideram que as diferentes agências do governo percebem e agem diante de tal incerteza de forma distinta, tornando muito problemáticas as reformas, sobretudo aquelas que tentam aplicar procedimentos homogêneos, desconsiderando as diferenças entre as diversas agências. Kaufman (1995), Peters e Savoie (1996) relacionam a falha seqüencial à tensão entre descentralização e problemas de coordenação. As políticas de reforma usualmente trazem em si forças centrípetas e centrífugas que as tornam de alta complexidade de implementação. As forças centrípetas usualmente tendem a descentralizar os processos decisórios e os mecanismos de controle no sentido de elevar a performance. Por outro lado, as forças centrífugas tendem a ressaltar a necessidade de fortalecer a capacidade de coordenação central da formulação das políticas públicas. Neste sentido, a coordenação se torna problemática. Peters e Savoie (1996) argumentam que na experiência inglesa com as Next Step Agencies e nas Special Operating Agencies no Canadá, as chances para a falha sequiencial são consideráveis, dado que a coordenação é problemática. A fragmentação dos mecanismos de controle tende a produzir uma "incoerência entre as políticas públicas" (policy incoherence), e, em última instância, uma reduzida capacidade efetiva de exercer controle sobre tais agências.

Analisando as experiências de reformas voltadas para a performance na Inglaterra e Nova Zelândia, Polidano et al (1997) consideram que a tensão entre descentralização e coordenação é a razão principal para a falha seqüencial. Estes autores consideram que o elevado grau de descentralização, introduzido pelo modelo das PBOs, ampliou os riscos da 
falha seqüencial, dado que o governo central perdeu em muito sua capacidade de coordenar efetivamente um amplo número de agências administrativas que atuam de modo muito descentralizado. A descentralização gerou uma demanda maior por coordenação do governo central, o que gera, em última instância, uma maior necessidade por controle. Os autores argumentam que nos dois casos (e predizem para as reformas centradas nos princípios da New Public Management) existem dois fatores explicativos para o problema da falha sequiencial. Primeiro, existe um trade-off permanente entre a coerência estratégica de longo-prazo e os objetivos operacionais das agências administrativas. Em segundo lugar, existe um trade-off entre a ampliação do raio de controle (span of control) na administração central e os propósitos de redução de raios de controle mais gerenciáveis nas unidades descentralizadas, por meio de uma mais precisa definição das missões, dos objetivos operacionais e dos papéis das agências em produzir serviços, o que produz conflito e tensões potenciais para o sucesso da implementação das reformas baseadas em tal modelo.

Seidman (1998) argumenta que os conflitos de poder entre atores envolvidos na reforma explicam a falha sequiencial. Pelo fato de que as reformas buscam promover alterações substanciais no modo pelo qual o poder está organizado, estas produzem conflitos que giram em torno de questões relatadas ao problema de quem controla quem, ou ao problema do controle burocrático. O poder de controlar se torna a principal questão em torno do qual os atores se organizam em uma reforma. Embora a elevação da performance seja o motivo revelado, é exatamente sobre a questão do controle que os atores desenvolvem respostas cooperativas e não-cooperativas às propostas de reformar a administração pública.

Outro tipo de explicação coloca o problema da contradição entre os objetivos da reforma como fator causal de importância para a falha sequiencial. Seidman (1994), analisando as falhas no processo de transformação do Bureau of the Budget no Office of Management and Budget $(O M B)$, demonstra que a incompatibilidade entre os dois principais objetivos da agência — a gestão e o orçamento - foi o principal obstáculo para sua reforma. Ele explica que a principal dificuldade em transformar o Bureau of the Budget no $O M B$ foi a resistência da agência em incorporar a função management. Segundo ele, desde 1972, havia na agência uma subordinação da função gestão à função orçamento, de modo que a reforma, integrando estas funções percebidas como contraditórias, levou a reforma ao colapso em 1994.

Brunsson e Olsen (1993) e March e Olsen (1983) se alinham com o argumento da contradição entre os objetivos, e consideram que a falha sequiencial das reformas é produzida por "demandas conflitantes", as quais são geradas pela presença de dois objetivos em permanente tensão: a demanda por mudança e a demanda por estabilidade. Nesta mesma direção, 
enquadra-se o argumento clássico de Pressman e Wildavsky (1973), de que a falha seqüencial resulta de um problema de ação coletiva, dado a dificuldade de coordenação entre interesses das diversas agências administrativas em um processo de reforma. Mesmo quando não existe um elevado grau de conflito entre as agências com relação à reforma, a cooperação das agências se constitui um problema considerável.

O problema de implementação das reformas administrativas (e outras reformas dotadas de alto grau de incerteza e ambigüidade) reside no fato de que as organizações usualmente buscam outros interesses que não aqueles perseguidos pela reforma, o que torna mais complexo para o governo central obter a cooperação das agências administrativas. O problema da coordenação entre os múltiplos e diversos interesses faz com que as reformas usualmente sejam marcadas por altos custos de transação e por múltiplos problemas do tipo principal-agente (Williamson, 1985; North, 1990), produzindo incentivos para a falha sequiencial. No sentido de possibilitar a cooperação das agências em torno dos objetivos programáticos das reformas, é necessário mais controle e mais coordenação, sobretudo quando a diversidade dos interesses é muito alta. O sucesso das reformas no plano da implementação depende da criação de incentivos que tendam a gerar a cooperação entre principais e agentes (Kaufman, 1960).

Silverman (1997) também explica a falha seqüencial pela contradição dos objetivos das reformas. Em sua análise das políticas de reformas do serviço civil na África, ele demonstra que a contradição entre a estabilização fiscal e a melhoria da performance produziu um reduzido grau de cooperação dos atores estratégicos com a reforma. ${ }^{5}$ Ele considera que embora os dois objetivos sejam frequientemente colocados in tandem em programas de reformas, visando à performance, a experiência dos governos africanos sugere que existe uma tensão clara entre aqueles atores estratégicos que buscam a reforma a partir da mudança institucional, e os que buscam a partir da eficiência fiscal (Silverman, 1997: 164).

O Quadro 1 apresenta de forma detalhada o conjunto de explicações discutido neste capítulo, focalizando, nos tipos, mecanismos causais e nos argumentos utilizados pelos diversos autores.

\section{Quadro 1: Explicações para o problema da} falha sequiencial nas reformas administrativas

\begin{tabular}{|l|l|l|l|}
\hline Tipo de explicação & Autor(es) & Mecanismo causal & Argumento \\
\hline Institucionalização & $\begin{array}{l}\text { Caiden } \\
(1999)\end{array}$ & Instituições inibem reformas & $\begin{array}{l}\text { "reformas ocorrem em ambientes } \\
\text { altamente institucionalizados que } \\
\text { tornam as mudanças muito lentas e } \\
\text { com reduzida efetividade" }\end{array}$ \\
\hline $\begin{array}{l}\text { Resistência } \\
\text { organizada }\end{array}$ & $\begin{array}{l}\text { Kaufman } \\
(1995)\end{array}$ & $\begin{array}{l}\text { Resistência organizada inibe } \\
\text { reformas }\end{array}$ & $\begin{array}{l}\text { "reformas enfrentam resistência } \\
\text { organizada por três razões: a) os } \\
\text { benefícios gerados pelo status quo; } \\
\text { b) oposição calculada ; e c) reduzida } \\
\text { habilidade para a mudança" }\end{array}$ \\
\hline
\end{tabular}


continuação

\begin{tabular}{|c|c|c|c|}
\hline Tipo de explicação & Autor(es) & Mecanismo causal & Argumento \\
\hline Ondas de reforma & $\begin{array}{l}\text { Light } \\
(1997)\end{array}$ & $\begin{array}{l}\text { Efeitos não-intencionais causam a } \\
\text { necessidade por mais reformas }\end{array}$ & $\begin{array}{l}\text { "reformas geram mais reformas; } \\
\text { quanto mais o governo é reformado, } \\
\text { mais o Congresso e a Presidência } \\
\text { consideram mais necessidades por } \\
\text { reformas" }\end{array}$ \\
\hline $\begin{array}{l}\text { Conflito de } \\
\text { princípios }\end{array}$ & $\begin{array}{l}\text { Kaufman } \\
(1971)\end{array}$ & $\begin{array}{l}\text { O conflito de princípios sobre como } \\
\text { reformar gera a necessidade por mais } \\
\text { reformas }\end{array}$ & $\begin{array}{l}\text { "as políticas de reformas trazem em si } \\
\text { um conflito de princípios sobre como } \\
\text { reformar: a competência neutra, a } \\
\text { representatividade e a liderança exe- } \\
\text { cutiva, que torna as reformas incom- } \\
\text { pletas" }\end{array}$ \\
\hline $\begin{array}{l}\text { Conflito } \\
\text { estrutural }\end{array}$ & $\begin{array}{l}\text { Coe } \\
(1997)\end{array}$ & $\begin{array}{l}\text { O conflito estrutural entre os } \\
\text { objetivos produz o deslocamento } \\
\text { contínuo dos objetivos iniciais da } \\
\text { reforma }\end{array}$ & $\begin{array}{l}\text { "quando as reformas são } \\
\text { implementadas, outras forças, } \\
\text { operando no sentido de manter o } \\
\text { status quo, inibem as reformas" }\end{array}$ \\
\hline $\begin{array}{l}\text { Atenção dos } \\
\text { atores } \\
\text { estratégicos }\end{array}$ & $\begin{array}{l}\text { March et } \\
\text { al. (1993) }\end{array}$ & $\begin{array}{l}\text { A falta de atenção continuada para } \\
\text { os problemas da reforma gera falhas }\end{array}$ & $\begin{array}{l}\text { "as políticas de reforma não são } \\
\text { suficientemente capazes de manter a } \\
\text { atenção dos atores estratégicos por } \\
\text { um grande período de tempo" }\end{array}$ \\
\hline $\begin{array}{l}\text { Natureza da } \\
\text { reforma (múltiplos } \\
\text { objetivos, largo } \\
\text { escopo, alta } \\
\text { complexidade) }\end{array}$ & $\begin{array}{l}\text { March et } \\
\text { al. (1993) }\end{array}$ & $\begin{array}{l}\text { A existência combinada de objetivos } \\
\text { múltiplos, largo escopo e alta } \\
\text { complexidade nas reformas geram } \\
\text { problemas de cooperação }\end{array}$ & $\begin{array}{l}\text { "as reformas tendem a desencadear } \\
\text { processos reativos, dado seu grande } \\
\text { teor de incertezas, de complexidade e } \\
\text { resultados imprevistos" }\end{array}$ \\
\hline $\begin{array}{l}\text { Contradições, } \\
\text { ambigüidade e } \\
\text { incerteza }\end{array}$ & $\begin{array}{l}\text { Peters e } \\
\text { Savoie } \\
(1996) \\
\text { March e } \\
\text { Olsen } \\
(1989)\end{array}$ & $\begin{array}{l}\text { As reformas são políticas dotadas de } \\
\text { elevado grau de contradições, } \\
\text { ambigüidades e incerteza, que inibe } \\
\text { a cooperação dos atores com as } \\
\text { reformas. Forças contraditórias } \\
\text { inibem reformas }\end{array}$ & $\begin{array}{l}\text { "reformas demandam mais coordena- } \\
\text { ção e controle" } \\
\text { "reformas tendem a desencadear um } \\
\text { conjunto de forças centrípetas e } \\
\text { centrífugas que, operando em } \\
\text { direções opostas, tendem a tornar as } \\
\text { reformas muito difíceis de } \\
\text { implementar" }\end{array}$ \\
\hline Garbage Can & $\begin{array}{l}\text { Cohen, } \\
\text { March e } \\
\text { Olsen } \\
(1972)\end{array}$ & $\begin{array}{l}\text { Incerteza, ambigüidade e } \\
\text { complexidade nas reformas causam } \\
\text { processos de "anarquias } \\
\text { organizadas" (garbage can } \\
\text { processes) que conduzem a falha }\end{array}$ & $\begin{array}{l}\text { "reformas são dotadas de alta } \\
\text { incerteza, complexidade e } \\
\text { ambigüidade, que produzem } \\
\text { dificuldade de cooperação" }\end{array}$ \\
\hline $\begin{array}{l}\text { Descentralização } \\
\text { x coordenação }\end{array}$ & $\begin{array}{l}\text { Kaufman } \\
(1995)\end{array}$ & $\begin{array}{l}\text { A tensão entre descentralização e } \\
\text { coordenação causam falha } \\
\text { seqüencial }\end{array}$ & $\begin{array}{l}\text { "processos de descentralização } \\
\text { produzem problemas de coordenação } \\
\text { entre principais e agentes, o que } \\
\text { demanda mais controle, produzindo } \\
\text { falha" }\end{array}$ \\
\hline $\begin{array}{l}\text { Diversidade de } \\
\text { interesses } \mathrm{x} \\
\text { One Size Fits All }\end{array}$ & $\begin{array}{l}\text { Diversos } \\
\text { autores }\end{array}$ & $\begin{array}{l}\text { Reformas falham por não considerar a } \\
\text { diversidade de interesses e } \\
\text { especificidades das agências do } \\
\text { governo }\end{array}$ & $\begin{array}{l}\text { "a alta diversidade de interesses das } \\
\text { agências administrativas reduz as } \\
\text { chances de cooperação com políticas } \\
\text { de reformas centradas em modelos } \\
\text { mais uniformes" }\end{array}$ \\
\hline $\begin{array}{l}\text { Dilemas de } \\
\text { ação coletiva }\end{array}$ & $\begin{array}{l}\text { Pressman } \\
\mathrm{e} \\
\text { Wildavsky } \\
(1973)\end{array}$ & $\begin{array}{l}\text { Problemas de ação coletiva entre as } \\
\text { agências do governo produzem } \\
\text { problemas de cooperação, que, por } \\
\text { sua vez, produz falha sequiencial }\end{array}$ & $\begin{array}{l}\text { "as reformas produzem dilemas de } \\
\text { ação coletiva, e, portanto, geram mais } \\
\text { demanda por coordenação e controle" }\end{array}$ \\
\hline Poder & $\begin{array}{l}\text { Seidman } \\
(1998)\end{array}$ & $\begin{array}{l}\text { A reação das agências a mudanças na } \\
\text { forma que o controle está organizado } \\
\text { produz falha seqüencial }\end{array}$ & $\begin{array}{l}\text { "os conflitos em torno de quem } \\
\text { ganha e quem perde poder com as } \\
\text { reformas produzem obstáculos à } \\
\text { mudança" }\end{array}$ \\
\hline $\begin{array}{l}\text { Contradição } \\
\text { de funções }\end{array}$ & $\begin{array}{l}\text { Seidman } \\
(1996)\end{array}$ & $\begin{array}{l}\text { A contradição dos objetivos } \\
\text { programáticos das reformas produz } \\
\text { falha seqüencial }\end{array}$ & $\begin{array}{l}\text { "objetivos conflitantes produzem } \\
\text { falha seqüencial nas reformas" }\end{array}$ \\
\hline $\begin{array}{l}\text { Absorção das } \\
\text { incertezas }\end{array}$ & $\begin{array}{l}\text { Desveaux } \\
(1994)\end{array}$ & Incerteza produz falha seqüencial & $\begin{array}{l}\text { "reformas geram alta incerteza nos } \\
\text { diversos atores, que torna mais } \\
\text { complexa e mais difícil a mudança na } \\
\text { direção desejada" }\end{array}$ \\
\hline
\end{tabular}




\begin{tabular}{|l|l|l|l|}
\hline Tipo de explicação & Autor(es) & Mecanismo causal & Argumento \\
\hline $\begin{array}{l}\text { Altas } \\
\text { expectativas }\end{array}$ & $\begin{array}{l}\text { Peters e } \\
\text { Savoie } \\
(1996)\end{array}$ & $\begin{array}{l}\text { Elevada expectativa dos atores em } \\
\text { relação às reformas inibem a mudança }\end{array}$ & $\begin{array}{l}\text { "reformas produzem elevadas expec- } \\
\text { tativas quanto aos seus impactos, o } \\
\text { que produz dificuldade de coopera- } \\
\text { ção dos atores com a mudança" }\end{array}$ \\
\hline $\begin{array}{l}\text { Demandas } \\
\text { conflitantes }\end{array}$ & $\begin{array}{l}\text { Brunson } \\
\text { e Olsen } \\
(1993)\end{array}$ & $\begin{array}{l}\text { As demandas conflitantes entre } \\
\text { mudança e estabilidade produzem } \\
\text { incertezae e ambigüidade, que } \\
\text { causam falha seqüiencial. }\end{array}$ & $\begin{array}{l}\text { mudança e estabilidantes entre a } \\
\text { processo de reforma geram falha" }\end{array}$ \\
\hline
\end{tabular}

Fonte: Elaboração do autor.

\section{O dilema do controle e as reformas gerenciais dos anos 90}

Um conjunto expressivo de experiências nacionais de reforma administrativa consolidou uma nova onda de reformas no setor público nos anos 90. Esta nova onda foi centrada nas idéias do New Public Management (a Nova Gestão Pública), no qual as reformas deveriam produzir um setor público com maior performance e mais voltado para atender aos cidadãos com melhores serviços públicos. Este princípio produziu as reformas gerenciais na Nova Zelândia, na Austrália, o Next Steps na Inglaterra, o National Performance Review nos EUA e a reforma gerencial de 1995, no Brasil. Salvaguardadas as diferenças nacionais, estes programas pretendiam atingir seus objetivos por meio de dois mecanismos complementares: primeiro, realizar medidas concretas de ajuste fiscal, implementando iniciativas voltadas para o controle e redução dos gastos com o aparato burocrático; e, segundo, realizar uma mudança institucional, visando criar uma nova estrutura institucional para organizar o funcionamento da administração pública orientada pela performance. Essas reformas tiveram quase sempre o slogan de elevar a performance e reduzir os custos (work better and cost less) do setor público, porém, no plano da implementação, nem sempre essas reformas conseguiram a cooperação necessária para a sua sustentabilidade para cada um dos objetivos, e muito ainda tem que ser feito para atingir a melhoria da performance no setor público. É exatamente pela contradição entre estes dois objetivos, em termos da necessidade do controle, que reside a raiz da falha sequiencial.

O caso brasileiro de implementação da reforma no período 19951998, foi, a meu ver, um caso típico em que a agência implementadora da reforma, o MARE, não conseguiu a cooperação simultânea dos atores estratégicos na arena da reforma para com os objetivos da reforma, dado o Dilema do Controle. O Dilema do Controle resultou em um padrão dual de cooperação, no qual o ajuste fiscal foi privilegiado, inibindo as chances 
de modelos de transformação nas instituições e no funcionamento do setor público, especialmente na sua estrutura de delegação e controle entre formulação e implementação de políticas públicas, herdado da reforma administrativa de 1967, em que a descentralização foi o eixo transformador da reforma. O paradoxo de implementação das reformas gerenciais, gerado pelo Dilema do Controle, pode ser compreendido a partir do impasse no que se refere a necessidade por controle em cada um dos objetivos. $\mathrm{O}$ ajuste fiscal demanda mais controle sobre a burocracia e suas organizações, no sentido de promover o uso devido de recursos, bem como a prestação de contas e o controle orçamentário. Por outro lado, a mudança institucional, especialmente aquela que pretende ampliar o escopo da descentralização, autonomia e responsabilidade, passa por uma necessidade de "descontrolar" a burocracia, dotando-a de maior autonomia gerencial e maior responsabilidade.

Neste sentido, as reformas sinalizam incentivos contraditórios para os principais atores estratégicos na sua arena de política pública, dificultando a cooperação simultânea destes para com os objetivos da reforma, e, conseqüentemente, reduzindo suas chances de implementação e a sustentabilidade. A cooperação para com os objetivos da reforma depende do modo específico de como os atores estratégicos alinham seus interesses em torno da questão controle. À medida que o ajuste fiscal demanda, sobretudo em contextos de muito baixa performance e de intensa pressão por uma redução dos gastos com o governo, maior controle sobre os meios e procedimentos, a mudança institucional demanda "menos controle". As reformas, sobretudo em contextos de baixa performance e grandes ganhos com a manutenção do status quo, usualmente conseguem apoio para o ajuste fiscal, dado que a cooperação com a redução dos gastos públicos deixa intacto o conjunto de práticas institucionais que, de fato, produzem os problemas crônicos de performance. Nos casos em que os atores estratégicos no interior da burocracia acumulam poder com a baixa performance decorrentes da "ordem institucional" existente, a mudança institucional é "usualmente relegada ao segundo plano nas políticas de reformas".

As reformas gerenciais colocaram como eixo transformador a transição de um modelo de gestão no setor público burocrático, no qual a accountability estava centrada nas regras (rule-based accountability), para a introdução progressiva da noção de gestão pelos resultados, i.e, a accountability orientada pela performance (performance-based accountability). No diagnóstico destas reformas, muito dos problemas da performance no setor público derivava da pouca orientação das organizações com os resultados a serem atingidos, mas sim com o cumprimento efetivo das regras e dos meios burocráticos. O Estado se 
tornara excessivamente burocrático e com precários mecanismos para promover suas políticas públicas. Por outro lado, era de fundamental importância criar instituições mais flexíveis, com maior participação de setores sociais capazes de articular melhor as demandas sociais por políticas públicas, rompendo com uma tradição burocrática de controles burocráticos pela estratégia de aumento da burocracia. Era preciso delegar e, ao mesmo tempo responsabilizar os diversos agentes públicos, controlando-os pela performance.

Reformar o setor público foi sinônimo de encontrar alternativas para propor uma transição de uma organização dentro do paradigma burocrático para modelos gerenciais, orientados pela performance. No paradigma gerencial, mudanças na forma de delegação e controle entre as agências do setor público, introduzindo maiores necessidades de produzir accountability, autonomia e responsabilidade, assumiram centralidade. A necessidade de elevar a performance, propondo um novo modelo de gestão entre a formulação e implementação de políticas públicas, criando as chamadas Performance Based Organizations (PBOs), para atuar como modelos descentralizados de provisão de serviços públicos, foi uma das tônicas dessas políticas de reformas. No Brasil, este novo modelo de delegação e de controle tomou forma com a proposta do Plano Diretor de 1995, em criar Organizações Sociais e Agências Executivas em diversos setores da burocracia, de acordo com um novo papel para o Estado brasileiro. Estas organizações deveriam ser responsáveis por funções de implementação de políticas públicas, controladas pelas agências centrais com base em mecanismos de controle da performance (os contratos de gestão).

Ao mesmo tempo em que a necessidade de delegar funções para as $P B O s$ demanda uma revisão dos padrões de relacionamento com as agências formuladoras, o controle pela performance eleva os riscos de uma grande fragmentação institucional, exacerbando o problema de coordenação entre principais e agentes, tal qual preconizado pelas recentes teorias institucionais. Os riscos decorrentes desta fragmentação institucional nas reformas gerenciais mostram que são complexos os custos associados à coordenação institucional controlada pela performance. Mesmo no caso particular da experiência inglesa com as $P B O s$, que é a mais "consolidada" das reformas gerenciais, relatórios recentes, tais como o Massey Report, revelam o quão complexo é descentralizar e controlar pela performance. Três elementos são ainda incertos na relação entre controle e delegação:

a) a definição mais precisa sobre o padrão de relacionamento entre os ministérios (agências formuladoras) e as PBOs;

b) os elevados graus de incerteza quanto a quem deve ser controlável pela performance; e 
c) as dificuldades inerentes às definições sobre os padrões de performance que devem ser atingidos pelas diversas organizações. $\mathrm{O}$ quão controlar ou liberar os controles se mostra o tema central das reformas.

Em contextos em que existe um legado histórico de baixa performance, de experiências concretas de falhas sequienciais, e de uma relação direta entre descentralização e desequilíbrio fiscal, tal qual o caso brasileiro pós-reforma administrativa, a questão da performance foi associada em grande medida à questão da fragmentação, e dos riscos desta para o ajuste fiscal. A proposta do MARE, em introduzir uma nova matriz institucional descentralizada e operando sobre padrões regulados pela performance, inibiu a cooperação, levando a reforma a uma cooperação deliberada com uma estratégia de aumentar os controles burocráticos, potencializando o ajuste fiscal. Veremos que o dilema do controle foi uma das principais razões para a cooperação dual com a proposta de reforma gerencial e para a extinção do MARE em 1999.

\section{O dilema do controle e a cooperação dual na reforma gerencial brasileira}

Passados cinco anos, o MARE foi extinto e suas funções absorvidas por outro ministério, e a política de reformas foi substancialmente alterada. Da nova matriz institucional, regulada pela performance para o governo federal, poucas instituições foram criadas. Contudo, uma visível e efetiva sequiência de resultados no plano fiscal mostra que o setor público brasileiro conseguiu reverter uma tendência expansionista dos gastos públicos. A reforma teve ganhos expressivos em uma dimensão e reduzidos resultados na sua dimensão central: a mudança institucional. $\mathrm{O}$ que explica este fenômeno? A explicação para este fenômeno foi a da cooperação dual dos atores estratégicos, gerada a partir do dilema do controle. O MARE conseguiu obter substancial apoio dos atores estratégicos para o ajuste fiscal, e não obteve o mesmo êxito para suas políticas de mudança institucional.

A não-cooperação com a mudança institucional dos atores estratégicos no caso específico apresentou razões claras. Primeiro, a reforma não era uma proposta dotada de crédito por parte dos atores estratégicos, sobretudo em sua dimensão mudança institucional. A proposta de mudança institucional foi percebida pelos atores estratégicos como "uma ameaça a estrutura de controle burocrático" nas relações entre a administração direta e indireta no governo federal; e, ainda, a mudança institucional não foi percebida como um mecanismo capaz de produzir impactos de curto prazo no problema do equilíbrio fiscal. Atores que detinham maior poder decisório 
do que o MARE no interior da burocracia governamental, como a Casa Civil da Presidência da República, o Ministério da Fazenda e o Ministério do Planejamento e Orçamento, mais especificamente, percebiam a reforma administrativa como uma questão mais diretamente associada aos processos de redução de pessoal e de controle de custos com a máquina administrativa, do que ao processo de introdução de mudanças substanciais nos arranjos institucionais existentes, mesmo que estes fossem cruciais para a elevação da performance.

Por outro lado, o MARE tinha a posição de que a reforma, para além dos necessários controles sobre os gastos do governo, era essencialmente uma questão de mudança institucional, ou mais especificamente, uma questão de redefinição das históricas relações entre a formulação e implementação das políticas públicas que se organizaram desde o decretolei no 200/67. A proposta do MARE era a de criar as novas instituições no setor público, as chamadas Organizações Sociais e Agências Executivas, introduzindo um modelo orientado por resultados para os diversos setores burocráticos. $\mathrm{O}$ argumento dos policy-makers no MARE era o de que a mudança institucional elevaria a performance do aparato burocrático à medida que novos arranjos institucionais "corrigissem" as históricas distorções de formulação e a implementação de políticas públicas no Estado brasileiro, rompendo com os baixos níveis de performance. Em contrapartida, os principais atores no processo decisório não alinhavam com tal mecanismo para elevar a performance, e por tal razão, estes não cooperaram com a mudança institucional na mesma intensidade que os objetivos de ajuste fiscal, minando as possibilidades de implementação. A razão central para a não-cooperação destes setores com as reformas orientadas pela performance residia na questão do controle. A passagem seguinte ilustra, com clareza, tal impasse:

“(...) A Fazenda e o Planejamento e Orçamento são excelentes parceiros quando o MARE se volta para as questões de redução e controle dos gastos com o governo. Entretanto, estes se tornam muito reativos à reforma quando se trata de um novo desenho institucional para o Estado brasileiro. Eles não apóiam a mudança institucional porque eles pensam que esta irá quebrar com a lógica de controle e poder na burocracia federal. Eles têm uma percepção bastante estreita sobre a reforma, e pouco interesse em questões voltadas para uma melhor gestão e melhor performance no Estado brasileiro. Por esta razão eles não se interessam por mudanças institucionais, e apóiam com mais intensidade aquelas partes da política de reforma que estão mais associadas a lógica da contabilidade e do controle." (Diretor, Secretaria da Reforma do Estado, Entrevista Pessoal). 
O modo específico como os diversos atores se posicionam em torno da questão controle é o ponto-chave para explicar a não-cooperação. Os principais atores com poder de decisão no governo percebem a introdução de instituições descentralizadas, e os novos padrões de controle alterariam em muito os graus de uma burocracia excessivamente fragmentada, autônoma e com precários controles, regulando a formulação e implementação de políticas públicas. O Estado brasileiro sofria de um problema de excesso de autonomia e de descentralização. Muito era delegado, e poucos controles pelos resultados eram implementados. A proposta de criação das $P B O$ s pelo MARE era uma tentativa de superar a crise de delegação herdada do decreto-lei no 200/67, em que o Estado brasileiro tornou-se excessivamente descentralizado, fragmentado e capturado pelas agências implementadoras. A reforma era uma tentativa de redesenhar, com outras bases, o modelo de delegação e controle, com base na performance. Ao mesmo tempo que o novo modelo visava descentralizar, ele visava responsabilizar as agências por certos resultados sociais, o que inexistia no modelo brasileiro.

Os setores que defendiam o ajuste fiscal argumentavam que a excessiva descentralização do Estado brasileiro e a precariedade dos controles eram nocivas ao ajuste fiscal. Grande parte dos problemas fiscais derivava da descentralização e do grau de autonomia das agências administrativas. As organizações orientadas pela performance eram vistas como uma ameaça, e o modelo gerencial proposto teve poucas chances de implementação, uma vez que este pretendia dar autonomia e responsabilidade das agências para a gestão de seus recursos orçamentários, humanos, e sobre os seus resultados. Tais elementos colidiam frontalmente com a lógica e a natureza da ordem burocrática existente:

"na implementação das Organizações Sociais e Agências Executivas, o conflito central é com os Ministérios da Fazenda e do Planejamento, que ainda têm uma grande resistência às idéias gerenciais. A reação se baseia no fato de que existirá um claro risco do governo perder controle, sobretudo nas áreas de orçamento e recursos humanos, com a autonomia e a responsabilidade destas 'novas' instituições. O modelo gerencial e as novas instituições reguladas pela performance quebrariam com os mecanismos de controle, introduzindo o descontrole e a descoordenação na gestão destes recursos. Por tal razão, estes setores da burocracia não associam as novas instituições com a elevação da performance." (Diretor, SRE, Entrevista Pessoal).

O forte interesse dos atores estratégicos em realizar o ajuste fiscal foi outro fator limitante para explicar a reduzida cooperação com a mudança 
institucional. A proposta de reforma foi motivada em grande parte pelo fato de que o setor público havia chegado ao limite das suas energias fiscais, e a reforma se tornara o ponto central da agenda da política do governo. A preponderância do ajuste fiscal obstaculizou o importante elo causal entre a necessidade de mudança institucional e ajuste fiscal. $\mathrm{Na}$ realidade, muito dos problemas fiscais do governo brasileiro derivavam do modo específico de formação e crescimento burocrático, bem como dos mecanismos de controle. O setor público cresceu dentro de um modelo em que o Estado era o ator central do desenvolvimento, foi expandido em regimes autoritários em que não se tem uma maior necessidade de elevar a performance para atender a certas demandas sociais que o retorno à democracia no Brasil trouxe para o novo padrão de intervenção pública. Os anos 90 trouxeram à tona a necessidade de criar novas instituições que equilibrassem performance e desempenho fiscal. O novo modelo descentralizado colocou como necessidade imperiosa o fato de criar instituições que além de controladas de modo mais participativo pela sociedade, fossem controladas pelos ministérios de acordo com as políticas públicas definidas pelo governo central. O maior grau de autonomia orçamentária, de gestão de pessoal e do uso de recursos pretendia instaurar uma maior racionalidade individual no uso dos recursos, bem como os mecanismos de enforcement dos ministérios para controlar tais instituições pelos resultados. Todavia, a resistência dos ministérios à proposta foi decisiva, e residiu sobre o controle. Os ministérios temiam perder o controle histórico sobre as instituições.

As reações a não-cooperação com a mudança institucional se formam em torno de três grandes temas: controle, orçamento e cargos. Se para os diversos ministérios, a não-cooperação se fundamenta na possibilidade de perda de controle e de poder sobre as instituições; para as instituições da administração indireta, a cooperação com novas formas institucionais está vinculada ao risco de perder dotações orçamentárias em caso de reduzida performance. A não-cooperação foi dominante. A manutenção dos arranjos institucionais ex-ante, mantendo a tênue relação entre orçamento e performance, foi o ponto nelvrágico para explicar a não-adesão às propostas de transformação institucional orientadas pela performance. A proposta de alterar os mecanismos e a lógica da velha ordem institucional com uma proposta de uma "nova divisão de responsabilidades", visando elevação da performance, não encontrou resposta cooperativa.

\section{Conclusões}

Como evidenciado, a explicação adicional para a falha seqüencial de reformas administrativas reside no dilema do controle. A contradição entre os objetivos de mudança institucional e ajuste fiscal é decisiva para 
mostrar por que a elevação da performance não encontra cooperação "espontânea". Pelo contrário, os atores preferem manter as instituições e cooperar estrategicamente com o ajuste fiscal. Organizações implementando reformas visando à performance encontram todos os tipos de resistências a reformas, como é explorado por diversas linhas analíticas; todavia, a causa primária para a não-cooperação reside na tensão entre mais e menos controle.

Em condições de baixa performance e de forte interesse por ajuste fiscal, a cooperação com a mudança institucional se torna difícil. O que o caso revela é que os atores têm incentivos a cooperar com os objetivos de ajuste fiscal e reduzidos incentivos a promover mudança institucional. O mecanismo subjacente a esta estrutura de incentivos é a questão do controle. À medida que o ajuste fiscal pressupõe um aumento do controle sobre o aparelho burocrático, a mudança institucional pressupõe menos controle como um elemento necessário a performance. O dilema do controle é um dos poderosos mecanismos presentes nas reformas gerenciais, e foi um fator decisivo para explicar os problemas de implementação do MARE e a reforma gerencial de 1995, e penso, para o caso das falhas seqüenciais nas políticas de reformas administrativas mais amplamente.

A explicação apresentada parte da premissa de que em uma reforma orientada pela performance existe uma contradição entre os objetivos da mudança institucional e ajuste fiscal, a qual reside na relação entre performance e controle. Por um lado, as iniciativas de ajuste fiscal (redução e/ou controle dos custos visando a ganhos de eficiência fiscal) demandam mais controle sobre os sistemas burocráticos, ao passo que a mudança institucional demanda menos controle, sobretudo naquelas em que as propostas de descentralização são predominantes. Esta contradição dificulta a cooperação dos diversos atores estratégicos com o ajuste fiscal e a mudança institucional. Nas reformas orientadas pela performance, pelo simples fato de as instituições do governo central (as agências controladoras) terem o controle sobre os recursos humanos e orçamentários das instituições a serem transformadas em PBOs, estas tendem a perceber a criação dessas organizações como associada a menos controle, e, conseqüentemente, a menor performance, contribuindo para a resistência à reforma. Como visto, é questão do controle, e não da performance, e passa a ser fundamental para explicar a cooperação ou não das agências administrativas com propostas de reformas. Embora a elevação da performance seja a motivação aparente para as reformas administrativas, o modo específico pelo qual os diversos atores percebem e calculam os custos e benefícios gerados pela mudança da estrutura de organização do controle é fundamental para explicar o problema da falha seqüencial. Quanto mais uma dada política de reforma propõe alterar radicalmente a forma de controle que regula a relação entre implementação 

das reformas administrativas, sobretudo aquelas em contextos democráticos, de elevada fragmentação e descontrole, bem como marcados por um legado de reduzida performance como é o caso brasileiro.

$\mathrm{O}$ dilema do controle representa a raiz de um dos problemas estruturais nas reformas administrativas, qual seja a tensão entre performance e accountability, ou, mais amplamente, entre controle e delegação. $\mathrm{O}$ fenômeno da falha seqüencial nas reformas deriva em grande parte de como tal tensão está articulada no design da reforma, e a importante questão da cooperação dos diversos setores burocráticos com a mudança institucional podem ser explicadas em grande parte pela importante questão do controle. O elemento que orienta a ação, as escolhas e o comportamento estratégicos não se relaciona a performance, mas sim ao controle. Embora decisiva para melhoria da performance, a mudança institucional é a mais problemática parte das reformas administrativas, e creio, que para as reformas, de um modo mais amplo.

\section{Notas}

1 O estudo científico sobre as políticas de reforma (do qual o estudo das reformas administrativas representa caso particular) é uma tradição no campo das políticas públicas. Estes estudos assumem diferentes formas, métodos e propósitos. Quanto ao foco, existem três tipos clássicos: o estudo da formulação, ou do processo decisório; os estudos da implementação; e os estudos dos impactos. Quanto ao propósito, pode-se considerar que existem várias abordagens. Alguns se concentram sobre a existência das reformas, centrados na questão de "por que as reformas existem da forma que existem?"; outros se voltam para compreender a natureza substantiva de tais políticas, buscando respostas para a questão de "por que e como as reformas assumem uma dada forma?". Outros buscam compreender a lógica de produção e de funcionamento das reformas. O estudo dos impactos compreende estudos de avaliação ex-post dos resultados das reformas administrativas sob diversas dimensões.

2 Tradução do autor. No original: "All around the world the administrative state is being reexamined and reshaped (...) government is being transformed and reinvented, bureaucratic centralism is being abandoned, the welfare state is being downsized, the public sector is being reduced, public organizations are being reengineered, and public management is being reinvigorated. Governments have promised as much before but they too often failed to improve their performance simply because many reforms have proved disappointing (italics added). Reforms have failed to make any significant impact; they have gone wrong; they have been overtaken by events. The reformers have been too optimistic and often unrealistic; they have fallen into the traps of implementation. Reforms need strong political backing, mass support, and competent inside facilitation. Reformers need to take their time and accept what they can achieve even if the results fall short of their intentions". 
3 Meyer e Rowan (1977) argumentam que as estruturas burocráticas emergem e se desenvolvem em resposta às regras institucionais intencionalmente construídas. A grande tensão em reformar estas estruturas reside na fraca correspondência entre as estruturas e a performance. Neste sentido, os atores defendem a manutenção destas estruturas burocráticas diante da incerteza com as reformas voltadas para a performance. Em segundo lugar, as diversas formas de resistência às reformas são estratégias racionais, e têm alta probabilidade de ocorrência, especialmente porque as reformas são usualmente frágeis no que tange ao apoio político. As reformas no setor público têm reduzidas chances de ocorrência, uma vez que estas dependem do apoio político de coalizões muito complexas.

4 Tradução do autor. No original: "A host of forces tend to keep organizations doing the things they have been doing in the recent past, and doing them in just the way they have been doing them. The generally recognized collective benefits of stability and the opposition to change based on calculations of prevailed advantage, protection of quality, and the costs of modification furnish a thought-out foundation for resisting all efforts to reshape organizations or alter their behavior. Many factors weaken the ability of organizations to change (...) so formidable is the collection offorces holding organizations in their familiar paths that it is surprising that any changes ever manage to run the gauntlet successfully. Innovations and departures from the traditional seem unlikely to prevail over the odds against them. This is one of the reasons why many organizations die even though, presumably, they might alter themselves as conditions demand" (Kaufman, 1995).

5 A questão do ajuste fiscal assume centralidade nas reformas dos anos 90 , dado a evidência de que a grande maioria dos países passou a ter o pagamento da dívida pública como componente importante nos gastos públicos. Em 1994, o Brasil gastou aproximadamente 40\% dos gastos públicos na rubrica dívida. Dados comparativos mostram que em 1997 os EUA gastaram aproximadamente $15,2 \%$ dos seus gastos com a dívida, a Inglaterra aproximadamente 27,0 \%, a Nova Zelândia, 10,25 \%, e a Austrália, 19,5\%. Cf. IMF (1998).

\section{Referências bibliográficas}

Alexander, ER. (1989), "Improbable Implementation: The Pressman-Wildavsky Paradox Revisited”. Journal of Public Policy, no 9, p. 451-465.

Aucoin, Peter. (1990), “Administrative Reform in Public Management: Paradigms, Principles, Paradoxes and Pendulums". Governance, v. 3 (2), abril, p. 115-137.

Bresser Pereira, Luiz Carlos. (1996), "Da Administração Pública burocrática à gerencial". Revista do Serviço Público, ano 47, v. 120, no 1, jan-abr.

. (1997), “A Reforma do Estado dos anos 90: Lógica e Mecanismos de

Controle”. Cadernos MARE, no 1, Brasília.

. (1997), "Managerial Reform in Brazil's Public Administration". Paper presented to the Congress of the International Political Science Association - IPSA. Seul, agosto.

(1998), Reforma do Estado para a Cidadania: A Reforma Gerencial

Brasileira na Perspectiva Internacional. Brasília: Editora 34, ENAP

Bresser Pereira, Luiz Carlos; Peter, Spink (orgs). (1998), Reforma do Estado e Administração Pública Gerencial. Rio de Janeiro: Editora da Fundação Getúlio Vargas. 
Brunsson, Nils; Olsen, Johan P. (1993), The Reforming Organization. New York: Routledge.

CaIden, Gerald E. (1991), Administrative Reform Comes of Age. New York: Walter de Gruyter.

CAIDEn, Gerald E. (1999), “Administrative Reform - Proceed with Caution”. International Journal of Public Administration, v. 22 (6), p. 815-832.

Coe, Barbara A. (1997), "How Structural Conflicts stymie Reinvention. Public Administration Review, v. 57 (2), p. 168-173.

Desveaux, James A. (1994), “Antecipating Uncertainty: The Strategy-Structure Problem in Public Bureaucracy”. Governance, v. 7 (1), janeiro, p. 31-58.

FARAZMAnd, Ali. (1999), "Administrative Reform in Global Perspectives: A Symposium". International Journal of Public Administration, v. 22(6), p. 815-832.

Ferlie, Ewan; Ashburner, Lynn; Fitzgerald, Louis; Pettigrew, Andrew. (1996), The New Public Management in Action. Oxford: Oxford University Press.

Kaufman, Herbert. (1956), "Emerging Conflicts in the Doctrines of Public Administration". The American Political Science Review, v. 50, no 4, p. 1057-1073.

.(1995), The Limits of Organizational Change. New Brunswick: Transaction Publishers.

Kettl, Donald F. (1999), "Global Reinvention, Basic Issues, Questions Ahead". Paper presented in the Global Forum on Reinventing Government. Washington DC, p. 14-15.

Light, Paul C. (1997), Tides of Reform: Making Government Work 1945-1995. New Haven: Yale University Press.

March, James G., Olson, Johan P. (1983), “Organizing Political Life: What Administrative Reorganization Tells Us about Government”. American Political Science Review, v. 77, no 2 , p. 281-296.

Minogue, Martin; Polidiano, Charles; Hulme, David. (1998), Beyond the New Public Management : changing ideas and practices in governance. Edward Elgar Publishing Inc: Massachussets.

OlsEN, Johan P. (1988), “Administrative Reform and Theories of Organization”, in CAMPBELl, Colin S. J., Peters, Guy (eds.), Organizing Governance: Governing Organizations. Pittsburgh: University of Pittsburgh Press, p. 233-254.

Olsen, Johan P., Peters, B.Guy (ed.). (1996), Lessons from Experience: Experimental Learning in Administrative Reform in Eight Democracies. Scandinavian University Press.

Peters, Guy; Savoie, Donald J. (1996), "Managing Incoherence: The Coordination and Empowerment Conundrum”. Public Administration Review, v. 56 (3), p. 281-295. . (eds). (1993), Governance in a Changing Environment. Montreal: Canadian Centre for Management Development.

Peters, Guy B. (1991), "Government reform and reorganization in an Era of Retrenchment and Conviction Politics", in Ali Farazmand (ed.), Handbook of Comparative and Development Administration. New York: Marcel Dekker.

PfeFfer, Jeffrey; SALANCIK, Gerald R. (1978), The External Control of Organizations: A Resource Dependence Perspective. New York: Harper and Row.

Pollitt, Christopher. (1993), Managerialism and the Public Services: cuts or cultural change in the 1990s. Cambridge: Blackwell Business.

Pressman, Jeffrey; Wildavsky, Aaron. (1984), Implementation: How Great Expectations in Washington are Dashed in Oakland. Berkeley: University of California Press.

Rezende, Flávio da Cunha. (1996), “Os Leviatãs estão fora de Lugar”. Dados - Revista de Ciências Sociais, Rio de Janeiro, v. 39, no 2, p. 195-211.

. (1998), "Clinton e a Reinvenção do Governo Federal: O National

Performance Review”. Revista do Serviço Público, Brasília, ano 49, v. 1, jan-mar, p. 93-140. . (1998), “A Nova Gestão Pública, Performance e Reinvenção das Instituições: um desafio para a Reforma do Estado". Revista Reforma Gerencial, nº 4, novembro, p. 27-28. 

of External Support: MARE and the Reform of the State Apparatus in Brasil". Ph.D Dissertation. New York: Cornell University. Ithaca.

SAvore, Donald J. (1995), "Globalization, Nation States, and the Civil Service", in SAvore, Donald J., Peters, B. Guy (eds.), Governance in a Changing Environment. Montreal: Canadian Center for Management Development, p. 82-110.

Seidman, Harold. (1998), Politics, Position, and Power: The Dynamics of Federal Organization. New York: Oxford University Press. 
Revista do

Serviço

Público

Ano 53

Número 3

Jul-Set 2002

Flávio da Cunha

Rezende é

professor/

pesquisador de

mestrado em

Ciência Política

da Universidade

Federal de

Pernambuco;

$\mathrm{PhD}$ em

Políticas

Públicas e

Planejamento, pela Cornell

University,

Ithaca, EUA.

Contato:

fcrzen@

elogica.com.br

\section{Abstract}

\section{O dilema do controle e a falha sequiencial nas reformas gerenciais \\ Flávio da Cunha Rezende}

As políticas de reforma administrativa são casos clássicos de políticas que falham seqüencialmente. Reformas são iniciadas; todavia, estas se defrontam com problemas de implementação e são usualmente abandonadas, modificadas ou terminadas. A experiência contemporânea de reformas administrativas nos diversos Estados nacionais representa um legado histórico de falhas sequienciais. Este artigo discute o problema da falha seqüencial nas políticas de reforma administrativa, apresenta um amplo conjunto de explicações para tal fenômeno, e propõe uma explicação adicional ancorada na causalidade entre o dilema do controle e a falha sequiencial nas reformas. $\mathrm{O}$ artigo ainda discute como tal problema é nítido nas chamadas reformas gerenciais dos anos 90 , as quais possuem uma contradição relativa à demanda por controle, a qual produz, em certos contextos, incentivos positivos para a falha seqüencial. A primeira seção descreve o fenômeno da falha seqüencial nas políticas de reforma administrativa. A segunda parte se volta para apresentar o amplo conjunto de explicações disponíveis na literatura sobre tal fenômeno, com atenção especial para seus mecanismos causais e principais argumentos. Na seção final, apresenta-se a explicação adicional proposta e a aplicação para o caso da reforma gerencial brasileira de 1995 .

\section{EI dilema del control y la falla secuencial en las reformas administrativas Flávio da Cunha Rezende}

Las políticas de reforma administrativa son casos clásicos de políticas que fallan de forma secuencial. Son iniciadas reformas, sin embargo éstas enfrentan problemas de implementación, y son usualmente abandonadas, modificadas o terminadas. La experiencia contemporánea de reformas administrativas en los diversos Estados Nacionales representa un legado histórico de fallas secuenciales. Este artículo discute el problema de la falla secuencial en las políticas de reforma administrativa, presenta un amplio conjunto de explicaciones para dicho fenómeno y propone una explicación adicional apoyada en la causalidad entre el dilema del control y la falla secuencial en las reformas. El artículo discute también cómo dicho problema es nítido en las llamadas reformas administrativas de los años 90, las cuales poseen una contradicción relativa a la demanda por control, la cual produce, en determinados contextos, incentivos positivos para la falla secuencial. La primera sección describe el fenómeno de la falla secuencial en las políticas de reforma administrativa. La segunda parte se destina a presentar el amplio conjunto de explicaciones disponibles en la literatura sobre dicho fenómeno, con especial atención para sus mecanismos causales y sus principales argumentos. En la sección final se presenta la explicación adicional propuesta y la aplicación para el caso de la reforma administrativa brasileña de 1995

\section{Control dilemma and sequential failure in managerial reforms \\ Flávio da Cunha Rezende}

administrative reform policies are classical cases of policies leading to sequential failure. Reforms are begun but run into implementation problems and are usually abandoned, modified, or terminated. Contemporary administrative reforms in the different National States consist of a historical legacy of sequential failures. This article discusses the problem of sequential failure in administrative reform policies, provides a wide range of explanations 
the "control dilemma and the sequential failures in reforms." The article further shows how this problem is evident in managerial reforms of the 1990s, which contain a contradiction associated with the demand for control, which, in certain contexts, positively encourage sequential failure. The first section describes the sequential failure phenomenon in administrative reform policies. The second section sets forth a wide spectrum of explanations available in the literature on this matter, paying special attention to causal mechanisms and major arguments. The final section sets forth the additional explanation proposed and its application to the 1995 Brazilian managerial reform. 
